The important thing about the method of constructing the test piles is that this is the same method as will be used in due course to construct the piles for the bridge. Whether the skin friction values have been reduced by artesian pressure in the ground water as the Authors mention, or by penetration of bentonite slurry around the tube as the Writer suggests, below the value which might have been obtained had these factors been absent, is not known. However, the values obtained from the tests are those which should be used in design at this site.

\title{
REFERENCES
}

Golder, H. Q. \& Willeumier, G. C. (1964). Design of the main foundations of the Port Mann Bridge. Engng J. Can. 47, August, 22-29.

IIUtchinson, J. N. \& Jensen, E. V. (1968). Loading tests on piles driven into estuarine clays at Port of Khorramshar, and observations on the effect of bitumen coatings on shaft bearing capacity. Norwegian Geotechnical Institute, Publication 78, Oslo.

Woodward, R. J., Lundgren, R. \& Boitano, J. D. Jr. (1961). Pile loading tests in stiff clays. Proc. $5 t h$ Int. Conf. Soil Mech., Paris 2, 177-184.

\section{STRESS-PROBE EXPERIMENTS ON SATURATED NORMALLY CONSOLIDATED CLAY}

(Lewin, P. I. \& Burland, J. B. (1970). Géotechnique 20, No. 1, 38-56)

\section{R. H. G. Parry, University of Cambridge}

It is important in studying the stress-strain properties of clays to be able to separate the elastic and inelastic volume changes. The systematic series of stress probes on remoulded, anisotropically consolidated slate dust described by the Authors has done much to clarify these volumetric strains. In particular they have confirmed the concept of an elastic wall put forward by Roscoe and Schofield (1963). This concept maintains that during unloading the change in voids ratio is elastic and depends solely on the change in mean principal effective stress $p=\frac{1}{3}\left(\sigma_{1}^{\prime}+\sigma_{2}^{\prime}+\sigma_{3}^{\prime}\right)$. In effect, the elastic modulus at any time is assumed to be directly proportional to the mean principal effective stress, i.e.

$$
\delta v^{e}=\frac{\kappa}{1+e} \frac{\delta p}{p} \quad \cdot \quad \cdot \quad . \quad . \quad . \quad . \quad . \quad . \quad .
$$

where $\delta v^{e}$ is the unit elastic volume change and $\kappa$ is the initial slope of the swelling lines on an $e-\log p$ plot.

In earlier work (Parry, 1956, 1957, 1962), the following equation was used to separate elastic volume change from total volume change in triaxial tests on saturated remoulded Weald clay

$$
\delta v^{e}=\frac{(1-2 v) e}{k} \frac{\delta p}{p} \cdot \cdot \quad \cdot \quad \cdot \quad \cdot \quad \cdot \quad \cdot \quad \cdot \quad .
$$

The parameter $k$ and Poisson's ratio $\nu$ were taken to be constant and the term $(1-2 \nu) / k$ was evaluated from the initial slope of the swelling curves on an $e-p$ plot. As the variation of $e$ is negligible compared with the variation of $p$, equations (1) and (2) are almost identical.

Equation (2) was used to predict pore pressures developed at failure in undrained triaxial tests from volumetric parameters obtained in drained tests.

In addition, it was suggested by the Writer that in triaxial compression and extension tests carried out under constant $p$ conditions $\delta v^{e}$ should be zero. A number of tests of this type were carried out and the observed volumetric strains confirmed this.

It was also suggested by the Writer that under cyclic shear stressing the inelastic component of volumetric strain should rapidly disappear and the observed volumetric strains 
would then be wholly elastic. If cyclic loading was carried out under constant $p$ conditions both the elastic and inelastic volumetric strains, and hence the total volumetric strain, should tend to zero. A test of this type was performed on a normally consolidated sample, taking the deviator stress initially up to its peak value, then unloading and reloading to its peak value, and the following volumetric strains were observed:

$\begin{array}{ccc}\text { 1st loading } & \text { Unloading } & \text { Reloading } \\ -2 \cdot 3 \% & -0 \cdot 8 \% & +0 \cdot 2 \%\end{array}$

It can be seen that the volumetric strain on reloading was, as expected, very small.

\section{REFERENCES}

PARRY, R. H. G. (1956). Strength and deformation of clay. Ph.D. thesis, University of London.

Parry, R. H. G. (1957). Discussion. Proc. 4th Int. Conf. Soil Mech., London 3, $104-105$.

PARry, R. H. G. (1962). Volume changes in soils and their relation to sub-grade behaviour. Proc. 1s Conf. Aust. Road Res. Bal 1,722-729.

Roscoe, K. H. \& Schofield, A. N. (1963). Mechanical behaviour of an idealised wet clay. Proc. 2nd Euv. Mech. Conf. Soil, Wiesbaden 1, 47-54.

\section{B. LeLievre and B. Wang, Waterloo, Ontario}

The results reported by the Authors for a series of tests performed on saturated powdered slate dust are essentially in agreement with the results of tests on saturated kaolin previously reported by LeLievre and Poorooshasb (1967) and by Prasad (1968).

The main point to be discussed is the claim by the Authors that 'the normality condition of the plasticity theory provides a reasonable basis for the prediction of shear strain behaviour'.

The validity of such a claim depends upon whether one is chiefly concerned with approximations of stress-strain relationships for use in analytical applications, or whether one refers to the actual observed material behaviour.

Presuming that the Authors are considering material behaviour, then the Writers wish to point out the danger of making such a claim on the basis of limited evidence, and indeed it is difficult to see how this claim can be inferred from the results reported which show clearly the directions of the plastic strain increment vectors to be influenced strongly by the direction of the stress increment vectors.

Research has been carried out at the University of Waterloo since 1964 into the yielding and flow of cohesive soils in which the behaviour of the soil is being studied for both normally consolidated and overconsolidated states and including stress changes from compression to extension and vice versa.

Drained triaxial tests have been carried out on kaolin (obtained from Edgar, Florida) using both controlled deformation rate and controlled loading rate. The effect of creep in these two types of test was minimized by loading the samples in such a way as to limit the excess pore-water pressure within the sample to about $1 \mathrm{lb} / \mathrm{sq}$. in. throughout the duration of the test. Further, in stress controlled tests, each load increment was maintained until equilibrium conditions were virtually achieved. In this way all test results referred essentially to equilibrium states.

It appears that none of the proposals so far advanced, such as Calladine (1963), Roscoe and Burland (1968), and Prasad (1968), appears capable of explaining adequately the observed behaviour. To illustrate briefly some of the difficulties involved the following test results are provided. The stress and strain parameters used are identical with those of the Authors, namely

$$
\begin{array}{ll}
p=\frac{1}{3}\left(\sigma_{1}^{\prime}+2 \sigma_{3}^{\prime}\right) & \Delta \epsilon=\left(\Delta \epsilon_{1}-\frac{1}{3} \Delta v\right) \\
q=\left(\sigma_{1}^{\prime}-\sigma_{3}^{\prime}\right) & \Delta v=\left(\Delta \epsilon_{1}+2 \Delta \epsilon_{3}\right)
\end{array}
$$




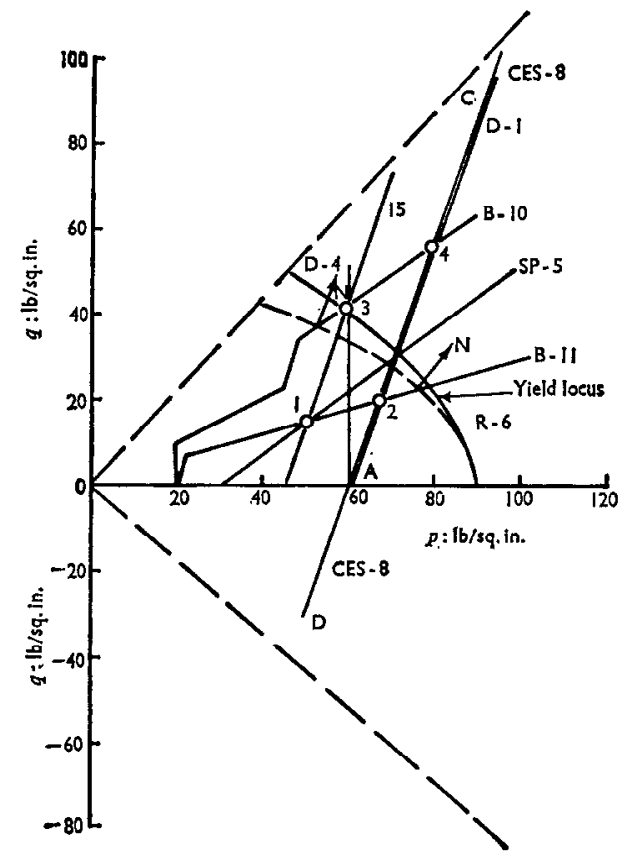

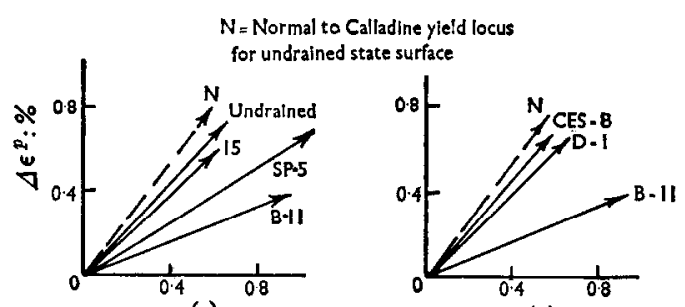

(a)

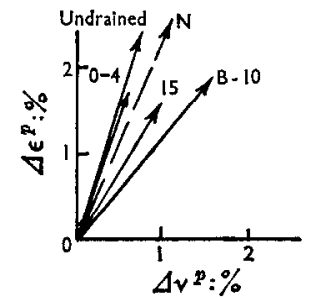

(c) (b)

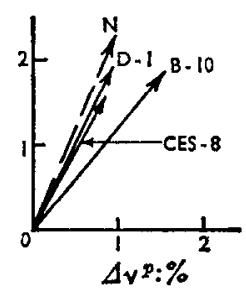

(d)

Fig. 1 (left)

Fig. 2 (above)

in which $\epsilon_{1}$ and $\epsilon_{3}$ are the natural axial and radial strains respectively, compressive strain being assumed positive.

Figure 1 shows the effective stress paths of some typical tests on normally consolidated kaolin plotted in $p, q$ stress space.

The directions of the plastic strain increment vectors for stress increments at the common points marked 1, 2, 3 and 4 as observed from the various tests indicated are shown in Fig. 2 . The plastic strains for both the volumetric and the distortional strains were obtained by deducting the associated recoverable strains from the observed total strain values. The vector $\mathrm{ON}$ in these figures represents the outward normal to the Calladine yield locus inferred from the undrained state boundary surface.

These results agree with those observed by the Authors and show the interdependency of the plastic strain increment vectors and the stress increment vectors. Thus strain paths for various tests predicted on the basis of the simple theory of plasticity can be significantly in error.

Typical state paths for both load-controlled and strain-controlled tests are shown in Fig. 3 where $p_{e}$ is the value of the stress on the virgin isotropic consolidation line corresponding to the value of the voids ratio $e$ of the sample at any instant. These curves are the two-dimensional representation of the state boundary surface. The results show that the state boundary surface obtained from strain-controlled drained tests, load-controlled drained tests and undrained tests are distinctly different, the load-controlled drained surface lying closer to the undrained surface than the strain-controlled drained surface. The strain-controlled drained surface frequently differs significantly from the load-controlled drained surface due to the nonequilibrium values of volume change. Under these circumstances, caution is required when inferring the directions of strain increment vectors from rate tests to check the validity of any normality condition.

To indicate briefly the influence of previous stress history on the direction of the plastic strain increment vectors, the following test results are given. A drained extension test CES-8 


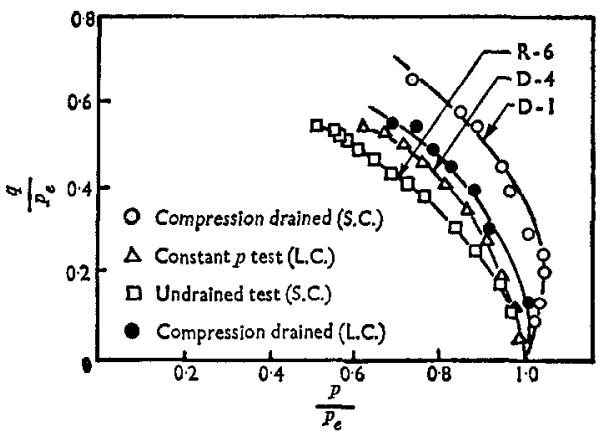

Fig. 3 (above)

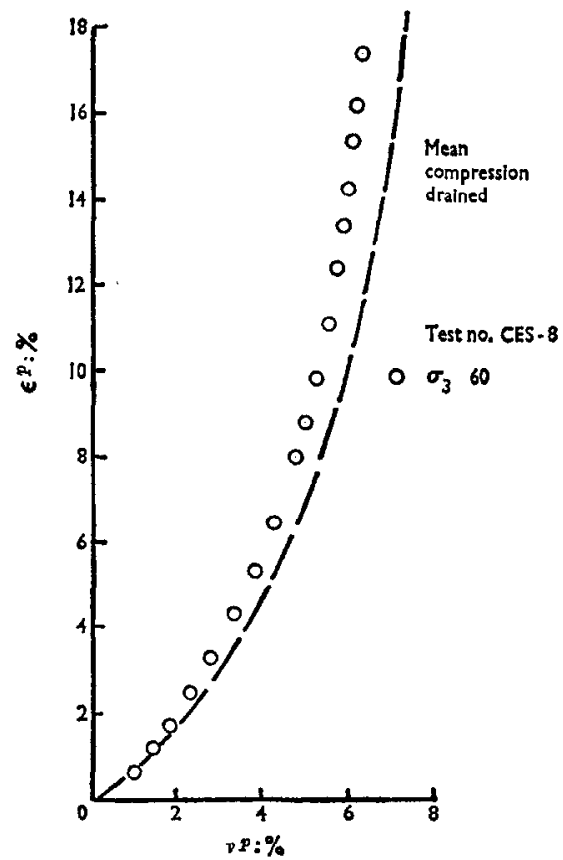

Fig. 4 (right)

was carried out initially under constant cell pressure along effective stress path AD until a value of $-q=30 \mathrm{lb} / \mathrm{sq}$. in. was reached as shown in Fig. 1. The sample was then unloaded from $\mathrm{D}$ along the effective stress path DA by controlling the stresses appreciably. A conventional triaxial compression test was then carried out on this sample to follow the effective stress path AC. The plastic strains induced in the sample during this test for the effective stress path AC are compared in Fig. 4 with the plastic strains measured during a conventional drained test on a sample consolidated under the same cell pressure. These results show that the direction of the plastic strain increment vectors for the conventional drained test path are not influenced appreciably by the previous stress history.

It appears therefore that much more work needs to be done before the complete picture of the yield and flow of cohesive soils will emerge.

\section{REFERENCES}

Calladine, C. R. (1963). Correspondence on A theoretical and experimental study of strains in triaxial tests on normally consolidated clays. Géotechnique 13, No. 3, 250-255.

LeLievre, B. \& PoORoOSHASB, H. B. (1967). Strains in triaxial compression of normally consolidated clays. 3rd Pan.-Am. Conf. Soil Mech., Venezuela, 398-409.

PRASAD, G. D. (1968). The influence of stress history on the yielding and flow of cohesive soils, Ph.D. thesis, University of Waterloo.

RosCOE, K. H. \& BURLAND, J. B. (1968). On the generalized stress-strain behaviour of 'wet' clay. Symposium on engineering plasticity, pp. 535-609. Cambridge University Press.

\section{P. I. Lewin and J. B. Burland}

Le Lievre and Wang have re-stated their evidence (referred to in the Paper) supporting the conclusion that the direction of the plastic strain increment vector is not independent of the 
direction of the stress increment vector. Clearly any analytical model that describes the complete picture of the yield and flow of clay must take account of the rotation of the plastic strain increment vector as well as such phenomena as creep and time-hardening. While recognizing that the concepts of simple plasticity do not take account of these factors, the Authors were of the opinion (subsequently endorsed by Naylor, 1970) that the agreement between the observed and predicted shear strains shown in Fig. 11 of the Paper is not unreasonable.

REFERENCE

Naylor, D. J. (1970). Correspondence on Stress-probe experiments on saturated normally consolidated clay. Géotechnique 20, No. 3, 336-339.

\section{BOOK REVIEWS}

Rheological aspects of soil mechanics. L. Suklje. 571 pp. John Wiley, London and New York, 1969. £7.

This is a most interesting book, written by an internationally acknowledged expert on soil mechanics. The range of topics covered is very wide, including some applications of the classical theories of elasticity and plasticity, failure theories, soil strength (in shear and in tension), stability analysis of slopes, and earth pressures on retaining walls and foundations, in addition to the more obvious subjects of consolidation of soils and settlement analysis.

The various theories of consolidation of saturated and partly saturated soils are described in terms of rheological models where possible, although Professor Suklje's own method of isotaches is also dealt with in detail. The latter method has the advantage that it is not restricted to any particular rheological model (linear or non-linear), but against this it appears to be empirical, difficult to apply and of unknown accuracy.

This part of the book (dealing with consolidation and settlement) is fairly comprehensive and yet such topics as organic soils and the importance of physico-chemical effects in soils are not specifically discussed. There is also a lack of information regarding the behaviour of fullscale foundations and earth structures.

This is not a book for beginners or for those of very limited mathematical ability. While it might be included in a list of textbooks for a post-graduate course in soil mechanics it seems likely that the majority of its readers will be engaged in research. To these it can be recommended for the breadth of its survey of theoretical soil mechanics.

Professor Suklje has stated that the aim of the book is 'to clarify the applicability of various methods and the influence of various rheological factors, and to facilitate the choice of appropriate simplifications'. It cannot be claimed that this aim has been fully achieved. Consequently foundation engineers will not be able to use this as a reference book or handbook to which they can turn for ready-made solutions to their problems.

A valuable feature is Professor Suklje's ability to draw on research contributions from all parts of the world, including Russia, and to provide a summary of these in English for those who are less gifted linguistically.

A good list of references and a supplementary bibliography are included.

I.F.C. 